\title{
A multicenter, randomized controlled comparison of three renutrition strategies for the management of moderate acute malnutrition among children aged from 6 to 24 months (the MALINEA project)
}

Muriel Vray ${ }^{1,2}$, Boris G. Hedible ${ }^{1}$, Pierrick Adam², Laura Tondeur ${ }^{2}$, Alexandre Manirazika ${ }^{3}$, Rindra Randremanana ${ }^{4}$, Halima Mainassara ${ }^{5}$, André Briend ${ }^{6,7}$, Cecile Artaud ${ }^{8}$, Cassandre von Platen ${ }^{8}$, Mathias Altmann ${ }^{9}$

and Ronan Jambou ${ }^{10^{*}}$

\begin{abstract}
Background: The aim of this open-label, randomized controlled trial conducted in four African countries (Madagascar, Niger, Central African Republic, and Senegal) is to compare three strategies of renutrition for moderate acute malnutrition (MAM) in children based on modulation of the gut microbiota with enriched flours alone, enriched flours with prebiotics or enriched flours coupled with antibiotic treatment.

Methods: To be included, children aged between 6 months and 2 years are preselected based on mid-upper-arm circumference (MUAC) and are included based on a weight-for-height Z-score (WHZ) between -3 and -2 standard deviations (SD). As per current protocols, children receive renutrition treatment for 12 weeks and are assessed weekly to determine improvement. The primary endpoint is recovery, defined by a WHZ $\geq-1.5 \mathrm{SD}$ after 12 weeks of treatment. Data collected include clinical and socioeconomic characteristics, side effects, compliance and tolerance to interventions. Metagenomic analysis of gut microbiota is conducted at inclusion, 3 months, and 6 months. The cognitive development of children is evaluated in Senegal using only the Developmental Milestones Checklist II (DMC II) questionnaire at inclusion and at 3, 6, and 9 months. The data will be correlated with renutrition efficacy and metagenomic data.
\end{abstract}

Discussion: This study will provide new insights for the treatment of MAM, as well as original data on the modulation of gut microbiota during the renutrition process to support (or not) the microbiota hypothesis of malnutrition.

Trial registration: ClinicalTrials.gov, ID: NCT03474276 Last update 28 May 2018.

Keywords: Moderate acute malnutrition, Prebiotic, Azithromycin, Microbiota, Metagenomic

\section{Background}

The main objective of this study is to improve the nutrition strategy used to treat moderate acute malnutrition (MAM). This is based on modulation of the gut microbiota with an adjunct product added to standard nutrition flours.

\footnotetext{
* Correspondence: rjambou@pasteur.fr

${ }^{10}$ Department of Parasites and Vector Insects, Institut Pasteur, 28 Rue du Dr. Roux, 75015 Paris, France

Full list of author information is available at the end of the article
}

\section{Undernutrition in Africa}

Child malnutrition in intertropical zones is a major public health problem. It favors the appearance of diarrhea but can also (1) disrupt the response to infection [1], (2) lead to an imbalance of the commensal flora and inflammation [2], and (3) modulate the response to vaccines [3]. These changes may also alter the cognitive development of children. Due to its life-threatening impact, programs provide care mainly for severe acute malnutrition (SAM), which is frequent in disturbed political contexts such as the Central African Republic (CAR) or during crop failure related to 
drought, like in Sahel. For example, in Niger, Action Contre la Faim Network (ACF) had to deal with 400,000 cases of SAM in 2013. However, aside from the emergency situation, SAM can develop in a context of chronic malnutrition (CM), such as in Madagascar, where $47.4 \%$ of children aged under 5 years are stunted [4]. MAM often happens during the first years of life when food is introduced in complement to breast milk. It can be managed at home and not at the hospital. However, if the management of the MAM changes over the last 30 years, the composition of flours has remained virtually unchanged. Indeed the time to recover is still long, and the percentage of success can be low [5], with high default rates or nonresponse to treatment, low coverage, and high associated costs [6-8].

\section{Malnutrition and microbiota}

Related to poverty and poor access to sanitation, infectious diseases are responsible for $25 \%$ of deaths worldwide, and diarrhea is the third deadliest infection, with approximately 525,000 per year for children aged under 5 years $[9,10]$. Diarrhea can modulate gut microbiota [11, 12] but an effect of an imbalance in the gut microbiota, regardless of diarrhea, on long-term child growth can also be important. This gut microbiota accounts for approximately $10^{12} \mathrm{mi}-$ croorganisms in humans, including bacteria, archae, yeast, viruses, and parasites. Gut microbiota can establish early in a child's life (may be even during pregnancy and delivery) and it can modulate diseases [13]. It changes greatly with the introduction of food [14]. Its composition also varies between industrialized and low/middle-income countries (LMICs) with an increased abundance of Prevotella species in developing countries compared to an increased abundance of Bacteroides in developed countries. [15-17]. In LMICs, urease-positive strains are enriched, indicating adaptations to the low-protein food that is consumed [17].

Recent studies have shown a link between SAM and the colonic microbiota composition [18-24]. During the first years of life, children with SAM have a significant delay in the maturation of the microbiota [23]. Changes in microbiota composition lead to "dysbiosis," marked by the enhancement of gut permeability and inflammation [25, 26]. Indeed, chronic inflammation induced by permanent stimulation due to food heavily contaminated by nonpathogenic or pathogenic bacteria could associated with villous atrophy, anorexia and malnutrition. These changes in microbiota could be a decrease in diversity or a shift in its composition as described in acute gastrointestinal infection $[27,28]$, inflammatory bowel disease [29, 30], coeliac disease [31-35], colon and liver cancer [36, 37], obesity [38], and diabetes [39].

The microbiota of non-stunted children looks enriched in probiotic species Bifidobacterium longum and Lactobacillus mucosae, whereas that of stunted children was enriched in inflammogenic taxa, including those in the genus Desulfovibrio and the order Campylobacterales [40]. Along the same line of reasoning, the metabolic impact of parasites such as Isospora belli, $\mathrm{Cy}$ clospora, Cryptosporidium, and Microsporidia in malnourished persons seems largely underresearched, but Giardia was recently associated with malnutrition [41].

During malnutrition, the disturbance of immunity may alter the response to vaccines, especially those administered orally (poliovirus, rotavirus, etc.) [2,3]. This reduced efficacy was confirmed during severe malnutrition, but is still being debated regarding moderate and chronic malnutrition. The impact of microbiota on brain function is also a major focus of research [42-46].

\section{How to modulate the microbiota: antibiotics versus prebiotics}

In malnourished children, clinical signs of infection can be attenuated. Indeed, the WHO recommends treatment of severely malnourished children with antibiotics [47]. Compared to standard flours, an increase in weight gain was described for children treated with flours + antibiotics [48]. In Malawi, a short-term effect of antibiotics on the nutritional recovery rate and mortality rate was confirmed for children with SAM [49, 50]. In Malawi, no effect of rifamixin on intestinal permeability was observed [49], whereas in Niger (Epicentre study), amoxicillin did not show any short-term benefit on the recovery rate of SAM compared with placebo [51]. However, hospital transfer rates decreased significantly. In Kenya, cotrimoxazole also failed to improve the clinical status of children with SAM [52]. The antibiotics can destroy gut microflora, but the effect on intestinal barrier integrity is still being debated [53].

Antibiotics can also restore equilibrium between the bacterial population induced by pathogenic bacteria. This has been described in the case of cholera, as a vibrio infection, and it results in a decrease in Bacteroidetes, Firmicutes, and Actinobacteria and an increase in harmful Proteobacteria. This disequilibrium was approached with treatment with macrolides; the abundance of Escherichia coli, Enterococcus, and Veillonella increased, while that of Bifidobacteria, Bacteroides, and Ruminococcus decreased [54].

However, the use of antibiotics for SAM children, even though recommended by the WHO, remains debated [55-59] both for its efficacy and for the possible increase in drug resistance [60]. To date, no trials have been performed on antibiotic use among MAM children. Firmicutes and other common gut microorganisms can contribute to fight by themselves against pathogens by local production of bacteriocins [61].

In the MALINEA (Malnutrition et Infection de l'Enfance en Afrique) protocol, macrolides were chosen to treat MAM based on (1) a narrower antibacterial spectrum of activity than other widely used antibiotics, (2) a rare use in 
dispensaries, especially as first-line treatment, which will prevent the emergence of resistant strains during mass administration, and (3) a favorable side-effect profile [62]. The main side effect of macrolides is gastrointestinal disturbance, which is less prevalent with azithromycin than with clarithromycin. For azithromycin, a long half-life and activity allows a 3-day treatment with a single daily dose $(20 \mathrm{mg} / \mathrm{kg} /$ day). Anti-inflammatory and immunomodulatory activities have also been reported. A benefit was also reported on neonatal growth when given to the mother [63]. In line, the recent MORDOR trial [64] showed the benefit of azithromycin alone on the mortality and clinical status of children.

Microbiota can also be modulated through several very different compounds called probiotics [65], prebiotics, and milk oligosaccharides [66]. Microbiota transplantation can also be used but is still experimental [67].

For probiotics (a specific strain of bacteria inoculated orally to the patient), the choice of species and, even more, the choice of strain to use, are very important and remain pitfalls for clinical trials [68]. The benefit of combination of probiotics + prebiotics can also be questioned, as in the PRONUT study [69].

On the other hand, prebiotics are mostly nondigestible carbohydrates, which serve as substrates, and they support proliferation of certain bacteria, such as bifidobacteria and lactobacilli. Early in life, they are provided by maternal milk through breast-feeding at the same time as commensal bacteria [70].

Unlike antibiotics, prebiotics do not modify the existing strains of bacteria but impact the proportions of the different groups of bacteria in the intestine (gut microbiota). The best-known prebiotics are (1) fructans (fructose polymers including inulin), which are present in many plants and extracted from chicory tubers [71], (2) fructo-oligosaccharides (FOS), obtained by hydrolysis of inulin or by biosynthesis from sucrose, and (3) fructose/galactose-containing oligosaccharides (galacto-oligosaccharides, GOS), which are natural products of human breastmilk. In children, most studies have used combinations of inulin and GOS [72]. Depending on the microbiota, they reach more or less distal parts of the colon before being metabolized by the resident bacteria [73, 74]. Prebiotics have been associated in several studies with profound changes in the microbial ecology of the gut and in a shift towards "healthier" communities [75]. Many studies have been conducted in animals and in human adults [76], and recent studies support a beneficial effect for HIV-infected children. In studies performed so far using the prebiotic inulin, the proportion of Lactobacillus spp., Bifidobacterium spp. [77, 78], and Faecalibacterium prausnitzii $[75,79,80]$ was shown to be increased during treatments, while the growth of Enterobacteriaceae and Clostridium spp. seemed to be restricted [78, 80, 81]. Prebiotics seemed to modulate lymphoid tissue associated with the intestine, resulting in improvement of inflammatory bowel symptoms in children or post-vaccine responses against measles [82-85]. Inulin consumption may improve the absorption of minerals in the colon, such as calcium, magnesium, zinc, and iron [86-88].

\section{Cognitive impairment}

Malnutrition is frequently associated with cognitive delay, compromising child development and education [89, 90]. An effect of the modulation of microbiota in the development of cognitive function in children can be suspected [91, 92]. Deworming by itself can affect the cognitive skills of children [93] but this could be due to an indirect effect on iron and anemia. The opportunity for modulating the intestinal microbiota, diarrhea or cognitive development with pre- or probiotics is also under study [94-97].

\section{Malnutrition is a major health problem in the four countries involved in the project}

The choice of the four countries in which to conduct this research is based on epidemiological data on moderate malnutrition, on existing facilities supported by ACF in the field and on the ability to perform high-level biological analysis in local laboratories. The countries selected in this project are particularly vulnerable to malnutrition and diarrhea. Programs are supported either by local facilities or through nongovernmental organizations (NGOs), especially ACF.

In Madagascar [4], acute malnutrition affects $8.6 \%$ of children aged under 5 years, including 1.4\% with severe forms. At weaning, the majority of children benefit from the introduction of food supplements but have a poorly diversified diet. Growth retardation begins in utero (13\% of children weigh less than $2.5 \mathrm{~kg}$ at birth) and increases at 12 months of age. Micronutrient deficiency is also a major public health problem in Madagascar that could increase the risk of morbidity and mortality [4].

In Niger, global acute malnutrition (GAM) has remained above the alert threshold $(10 \%)$ in recent years among children aged 6-59 months. For children aged 6 to 23 months, malnutrition regularly exceeds the emergency threshold of $15 \%$, as in 2005, $2010(22 \%)$, and 2011 (20.2\%). During the last 5 years, chronic malnutrition (CM) or growth retardation affected one of every two children in the country [97]. The overall underweight (weight- for-age) prevalence ranged between 32 and $40 \%$ over the past 5 years [98-101].

In 2014, in Senegal, the prevalence of GAM at the national level was $8.8 \%$. The prevalence in some departments, such as Ranérou, Podor, and Kanel, exceeds the critical threshold of 15\%. Sixteen departments of 45 have exceeded the threshold of 10\% GAM. Chronic malnutrition affects $15.5 \%$ of children aged 0-59 months [102]. 
In the CAR, in 2012, at a national level, the GAM prevalence rate was $8 \%$, and the SAM rate was $1.9 \%$. The CM rate was $38.7 \%[103,104]$. In addition to the progressive reopening of nutrition centers, mobile clinics are organized to screen children among the displaced in Bangui $(639,000$ displaced people; i.e., $12 \%$ of the total population) [105]. The country is in crisis, and only NGO interventions cover these emergencies [106].

\section{Methods and design}

\section{The aim}

The aim of this project is to define an easy-to-use modified strategy of renutrition to use in primary health centers to treat MAM before it degenerates into SAM. The main problem to tackle is that, in a peri-urban context, alimentation of small children is difficult to manage accurately, especially when food (or financial) resources are limited.

\section{The objectives}

The general objective of this project is to improve nutrition for children with moderate malnutrition using strategies to modulate intestinal microbiota. The objective of this three-arm, open-label, randomized multicountry study is to evaluate the effectiveness of two improved strategies of management of MAM in children aged between 6 months and 2 years in comparison with a reference standard of care. Recovery is defined by a (weight-for-height Z-score) $\mathrm{WHZ} \geq-1.5$ standard deviations (SD) after 3 months of treatment.

The secondary objectives are (1) to compare, for each group, all the measurements before and 3 months after intervention (weight, length, mid-upper-arm circumference (MUAC)); (2) to compare, between the three groups, the occurrence of clinical outcomes (intercurrent illness, hospitalization and transfer to the next level of care), the compliance to protocol, and tolerance (reported adverse and side effects, duration and intensity); and (3) to analyze the gut microbiota of the children during the renutrition process. In Senegal, psychomotor development will be assessed at inclusion and 3, 6, and 9 months after intervention using the DMC II (Developmental Milestones Checklist). DMC II scores will be compared (1) for the same child before and after intervention, (2) at inclusion between matched healthy children and malnourished ones from the same district, and (3) between arms at 3, 6, and 9 months.

The study design (protocol version 2_ 28 February 2018) According to centralized randomization, the children will receive one of the following:

Arm 1 (control): malted milk Prise en Charge de la MAM (PEC-MAM) flour + antiparasitic (albendazole)
Arm 2 (antibiotic): malted milk PEC-MAM flour + antiparasitic (albendazole) + azithromycin for 3 days Arm 3 (prebiotic): malted milk PEC-MAM flour + antiparasitic (albendazole) + inulin/FOS mixed with flour

A control group of well-nourished children without diarrhea aged 18 to 24 months will also be included to match the malnourished ones but without follow-up visits. The objective is to investigate microbiota of well-nourished children living in the same place and at the same time as the case group, to take into account local and seasonal variation of the microbiota. As only one stool sample will be obtained from non-stunted children, children under 18 months will not be included to discard the fluctuating composition of the microbiota at such young ages.

\section{Participants and enrollment}

In Niger, the study will be conducted in the department of Mayahi, in the municipalities of Tchake and Issawanne. In Tchake, the total population is 28,338 inhabitants, with 5668 children aged less than 5 years, and in Issawanne, the total population is of 45,152 inhabitants, with 9030 children aged under 5 years.

In Senegal, recruitment will be conducted in the district of Guédiawaye, near Dakar. The district is a low-income area of 355,525 inhabitants, with an average rate of MAM of $6 \%$. The primary health care center will be Hamo $V$, where an average of 500 MAM cases are followed each semester. A large team of community relay agents, led by nurses from the primary health care center, is in charge of the screening of MAM in the community.

In Madagascar, the study will take place in poor neighborhoods of Antananarivo. Two different structures run by local NGOs (CRENAM Andohotapenaka) and Centre de Santé Mitia are dealing with malnourished children.

In the CAR, the study will take place in Bangui in two private centers that support MAM: the St. Jacques and the St. Joseph's Health Centres. These centers are supported by the World Food Program, which provides nutritional supplements.

Prescreening of malnourished children aged between 6 and 24 months will be conducted in the country by community health workers using arm circumference (115 $\leq$ MUAC $<130 \mathrm{~mm}$ ). To be definitively included, children should have a WHZ between -3 and -2 SD, and should be followed for at least 3 months. Written consent from the parents or legal guardians will be obtained. Children not satisfying these criteria will not be included, nor will those (1) with complications requiring intensive clinical care (severe vomiting, hypothermia $<35^{\circ} \mathrm{C}$ or fever $>39^{\circ}$ $\mathrm{C}$, pneumonia, and severe anemia), (2) with extensive infections, (3) who are weak, apathetic or unconscious, and (4) or presenting fitting/convulsions, severe dehydration 
or any condition that requires an infusion or tube feeding. Children currently receiving one of the following treatments will also be excluded from entering the study: antacids, cetirizine, digoxin, ergotamine, zidovudine. Moreover, those with hypersensitivity to macrolides, flour or the prebiotics used during the study will also be excluded. HIV testing is not planned as its prevalence is very low in three countries out of four. For CAR systematic testing of young children for HIV was considered as a stigmatization of the mother by the National Ethic Committee which will induce refusal of the mothers to participate.

\section{Recruitment, randomization, and follow-up (Fig. 1 and Additional file 1)}

The enrollment will take place at the primary health center after weight and height assessment, signature of written consent from the parent or legal guardian, and verification of inclusion/exclusion criteria.

Randomization will be stratified by country, health center, and age (6-11 months versus 12-24 months). Randomization will be achieved in a 1:1 ratio using random permutation blocks. A clinical examination will be done, and stool samples will be collected. Systematic treatment with albendazole will be given to all children in the three arms aged older than 12 months after collection of the stools. For children treated with azithromycin, the first treatment will be given after stool collection at the dispensary. Doses for the following 2 days will be given at the health center as well.

After enrollment, in Senegal, children with MAM will be evaluated for cognitive development and ability, with a DMC II (Developmental Milestones Checklist) questionnaire applied by a trained social worker.
Children will be followed up weekly for 12 weeks and at 6 months (M6) at the health center. At each visit, (1) flours will be given to the caretaker for the whole week, (2) weight, height, and arm circumference will be assessed, and (3) a clinical examination will be carried out, and data on safety and child's food consumption will be investigated. In the case of a missing visit or insufficient weight gain, a visit at home will be organized by health workers to collect supplementary information.

At inclusion, 3 months (M3) and 6 months (M6), stool samples will be collected. After 6 months, the follow-up will be stopped except for in children involved in the psychomotor development evaluation protocol, who will be followed until age 9 months (M9). However, in the case of nonrecovery at M3, children will still receive follow-up care according to the national recommendations but will be considered "treatment failure."

\section{Interventions}

\section{Supplementary feeding}

Default of quality of flours obtained from the local market in African countries is a very common pitfall that is poorly addressed by NGOs. For the trial, flours will be produced by an industrial partner (PROTEIN KISSEE LA Zone industrielle, Vridi, Port-Bouet, 18 BP 2335 Abidjan). It is a well-established brand on the West African market providing ready-to-eat fortified complementary foods. The composition of the flours, described in Table 1, will be adapted to the international malted milk PEC-MAM standard [107].

\section{Antibiotics}

A vial of powder for oral suspension of azithromycin (600 mg) will be restored at $200 \mathrm{mg} / 5 \mathrm{~mL}$ and then given with a syringe for oral administration three times

\begin{tabular}{|c|c|c|c|c|c|c|c|c|c|c|c|}
\hline & & Enroln & & & & & & ow -up & & & \\
\hline \multirow{5}{*}{ Enrolment } & & Enrolment & J0 & $\mathrm{J} 1$ & $\mathrm{~J} 2$ & $\begin{array}{l}\text { Weekly visit } \\
\text { (W1 to W11) }\end{array}$ & $\begin{array}{l}\text { Final visit } \\
\text { (W12) }\end{array}$ & $\begin{array}{l}\text { Supplementary visit } \\
\text { (no recovery at W12) }\end{array}$ & $\begin{array}{l}\text { Control visit } \\
\text { (M6) }\end{array}$ & $\begin{array}{l}\text { Control visit } \\
\text { (M9)** }\end{array}$ & Close-out \\
\hline & Information /consent & $\mathbf{X}$ & & & & & & & & & \\
\hline & Inclusion criteria & $\mathbf{X}$ & & & & & & & & & \\
\hline & Pre-inclusion & $\mathbf{X}$ & & & & & & & & & \\
\hline & Treat assignment & & $\mathbf{X}$ & & & & & & & & \\
\hline \multirow{11}{*}{ Interventions } & Clinical examination & & $\mathbf{X}$ & & & $\mathbf{X}$ & $\mathbf{X}$ & $\mathbf{X}$ & $\mathbf{X}$ & & \\
\hline & Anthropometric data & & $\mathbf{X}$ & & & $\mathbf{X}$ & $\mathbf{X}$ & $\mathbf{X}$ & $\mathbf{X}$ & & \\
\hline & Stool sampling & & $\mathbf{X}$ & & & & $\mathbf{X}$ & & $\mathbf{X}$ & & \\
\hline & Cognitive assessment* & & $\mathbf{X}$ & & & & $\mathbf{X}$ & & $\mathbf{X}$ & $\mathbf{X}$ & \\
\hline & Flours & & $\mathbf{X}$ & & & $\mathbf{X}$ & $\mathbf{X}$ & $\mathbf{X}$ & & & \\
\hline & albendazole & & $\mathbf{X}$ & & & & & & & & \\
\hline & Arm 2 Azithromycin & & $\mathbf{X}$ & $\mathbf{X}$ & $\mathbf{X}$ & & & & & & \\
\hline & Arm 3 Prebiotic & & $\mathbf{X}$ & & & $\mathbf{X}$ & $\mathbf{X}$ & $\mathbf{X}$ & & & \\
\hline & Compliance checking & & $\mathbf{X}$ & & & $\mathbf{X}$ & $\mathbf{X}$ & $\mathbf{X}$ & $\mathbf{X}$ & & \\
\hline & Side effect registration & & $\mathbf{X}$ & & & $\mathbf{X}$ & $\mathbf{X}$ & $\mathbf{X}$ & $\mathbf{X}$ & & \\
\hline & quantity of food used & & $\mathbf{X}$ & & & $\mathbf{X}$ & $\mathbf{X}$ & $\mathbf{X}$ & $\mathbf{X}$ & & \\
\hline \multirow{3}{*}{ Assessments } & Monitoring & $\mathbf{X}$ & $\mathbf{X}$ & $\mathbf{X}$ & $\mathbf{X}$ & $\mathbf{X}$ & $\mathbf{X}$ & $\mathbf{X}$ & $\mathbf{X}$ & $\mathbf{X}$ & \\
\hline & Audit & & & & & & & & & & \\
\hline & Site supervision & & & & & & & & & & \\
\hline \multicolumn{12}{|c|}{$(*$ Senegal) } \\
\hline
\end{tabular}


Table 1 Composition of the flours

\begin{tabular}{|c|c|c|c|}
\hline & Without prebiotics & \multicolumn{2}{|l|}{ With prebiotics } \\
\hline \multicolumn{4}{|c|}{ Composition (\% of dry weight) } \\
\hline wheat & $62.4 \%$ & \multicolumn{2}{|l|}{$60.9 \%$} \\
\hline soya & $20.8 \%$ & \multicolumn{2}{|l|}{$20.3 \%$} \\
\hline sugar & $8 \%$ & \multicolumn{2}{|l|}{$8 \%$} \\
\hline dry milk & $7 \%$ & \multicolumn{2}{|l|}{$7 \%$} \\
\hline iodinated salt & $0.2 \%$ & \multicolumn{2}{|l|}{$0.2 \%$} \\
\hline vitamins and salts & $1.3 \%$ & \multicolumn{2}{|l|}{$1.3 \%$} \\
\hline flavor & $0.4 \%$ & \multicolumn{2}{|l|}{$0.4 \%$} \\
\hline Prebiotic & $0 \%$ & \multicolumn{2}{|l|}{$2 \%$} \\
\hline Total & $100 \%$ & \multicolumn{2}{|l|}{$100 \%$} \\
\hline \multicolumn{4}{|c|}{$\begin{array}{l}\text { Overall composition of the flour and additional compounds (for both } \\
\text { with and without prebiotic): composition per } 100 \mathrm{~g} \text { of flour }\end{array}$} \\
\hline calories (kcal) & 420 & ascorbic acid & 60 \\
\hline protein total (g) & 15 & thiamin & 1 \\
\hline lipids (g) & 9 & riboflavin & 1 \\
\hline carbohydrates & 66 & nicotinamide (mg) & 12 \\
\hline fibers & 2 & folic acid (mg) & 0.3 \\
\hline sodium (mg) & 200 & pantothenic acid (mg) & 4 \\
\hline calcium mg) & 266 & biotin $(\mu \mathrm{g})$ & 0.016 \\
\hline phosphorus (mg) & 200 & vitamin E (IU) & 10 \\
\hline potassium (mg) & 610 & vitamin $\mathrm{B} 12(\mu \mathrm{g})$ & 1.8 \\
\hline iron (mg) & 23.2 & vitamin A (IU) & 2668 \\
\hline copper (mg) & 0.18 & vitamin D (IU) & 400 \\
\hline zinc (mg) & 16.6 & vitamin B6 (mg) & 1 \\
\hline manganese (mg) & 2.4 & & \\
\hline
\end{tabular}

once a day over a maximum of 4 days (in case of 1 day missing) (20 mg/kg/day daily for 3 days). The same batch of antibiotics will be used in the four countries.

\section{Prebiotics}

The recommended doses with positive effects on the intestinal flora are between 2.5 to $10 \mathrm{~g} /$ day $[108,109]$. The main side effects are observed with doses more than $40 \mathrm{~g} /$ day, as the substances can cause bloating and induce intestinal cramps. Abdominal pain has been reported with doses of $10 \mathrm{~g} /$ day. For this study, we will evaluate the effectiveness of a combination of prebiotic inulin / FOS (Synergy1 $6 \mathrm{~g} /$ day if age $\geq 12$ months and $4 \mathrm{~g} /$ day if $<12$ months), as it is simple to be obtained (manufactured by BENEO, Tienen, Belgium) and is active at different levels of the digestive tract.

\section{Data collection}

\section{Clinical data}

At inclusion, a standardized questionnaire will be conducted with the parents or legal guardians to collect general characteristics, socioeconomic and clinical data.
At each visit, clinical assessment will be recorded until recovery and then at M6, data will be registered concerning undercurrent illness, signs of infections (diarrhea, vomiting, fever, cough), need to transfer to hospital, and safety and adherence to treatments (defined as completion of all 7 days of the study regimen).

\section{Anthropometric data}

The children will be monitored weekly for 3 months (or until recovery if treatment fails) at the primary health center. One additional visit is planned at 6 months. At each visit, weight, length, and MUAC will be measured. Balances will be from SECA UNICEF $( \pm 100 \mathrm{~g})$. Length will be measured on children placed in an elongated position using a Fathom Infant / Child ShorrBoard for infants aged less than 2 years $(130 \mathrm{~cm}$ with graduations of $0.1 \mathrm{~cm})$. MUAC will be measured with a UNICEF MUAC tape.

\section{Laboratory processes}

Stool samples will be collected during the day and stored at $4{ }^{\circ} \mathrm{C}$ until transportation to the laboratory. At laboratory, stools will be separated in aliquots and stored at $-80{ }^{\circ} \mathrm{C}$ until analysis. Stool examination will be based on metagenomic approaches. Whole deoxyribonucleic acid (DNA) will be extracted from stools using a procedure adapted for stools including bead fractioning and a QIAGEN stool extraction kit. Fragments of the $16 \mathrm{~S}$ gene will be polymerase chain reaction (PCR) amplified using V3/V4-adapted primers. Sequencing of the PCR products will be carried out on a Miseq Illumina machine. Metagenomic analysis will be conducted using the SHAMANN package. In parallel, direct detection of pathogens (Salmonella, STEC, Campylobacter, Vibrio cholerae, $V$ parahaemolyticus, $V$ vulnificus, Cryptosporidium sp., Entamoeba histolytica, Giardia lamblia, Microsporides sp., Adenovirus, Astrovirus, Norovirus, Rotavirus) will be done using specific quantitative-PCR (Q-PCR) and ELISA protocols in the Institut Pasteur de Madagascar, Institut Pasteur de Dakar, and Institut Pasteur de Bangui.

\section{Cognitive and motor development}

During this study, a Developmental Milestones Checklist II (DMC II) questionnaire will be administered to participating children to evaluate their cognitive and motor abilities. This questionnaire is adapted to children aged between 1 and 59 months and has been developed specifically to be used in developing countries and particularly in sub-Saharan Africa.

In Senegal, the DMC II will be applied during enrollment at inclusion and 3, 6, and 9 months, after enrollment. Eighty children with MAM and 80 healthy non-stunted children will be included in this specific phase. This questionnaire has already been used in several countries (Kenya, Bukina Faso, Mali). It can be applied by 
trained but unspecialized field workers and is fast to document (20-30 min). Adaptation of the questionnaire to the local context will be done during a preliminary study conducted at the Children's Hospital of Dakar.

\section{Evaluation criteria}

The primary endpoint is recovery, defined by WHZ $>-1.5$ $\mathrm{SD}$ at two successive examinations without hospitalization or undercurrent discharge to SAM or lost to follow-up. The main endpoint will be at 3 months. This is a stronger criteria of recovery than usual (WHZ $>-2$ ), which avoids misclassification of the children at the end of the intervention.

Secondary outcomes include anthropometric parameters (weight, length, and MUAC), time for recovery, and safety of the strategy, compliance to treatment and psychomotor development evolution (for Senegalese children).

The main biological secondary endpoint is to analyze the variations of microbiota and the presence of specific pathogens during the renutrition process. The major question is to understand if microbiota differ between well- and malnourished children and if renutrition retardation is related to a specific type of microbiota. Microbiota will be expressed as Operational Taxonomic Units (OTUs), and the results of Q-PCR as positive/negative.

\section{Statistical considerations}

Full details on data management and the database can be available on reasonable request to the corresponding author. Databases and confidentiality purposes were already approved by either the National Ethics Committees, the Pasteur Institute IRB or the French Office for Safety in Data Meaning (CNIL).

\section{Sample size}

Based on previous studies showing a recovery rate of between 50 and $88 \%$, we can assume a likelihood of nutritional recovery in the control arm of approximately $60 \%$ after 12 weeks. To show a benefit of at least $15 \%$ with antibiotics or prebiotics, with a type I error of 0.017 (Bonferroni correction for multiple comparisons), a power of $90 \%$ and a two-sided test, 840 children will be enrolled (280 per arm), with 210 in each country (with an allowance to loss of 10\%). After enrollment, in Senegal, 80 children with MAM will be evaluated and followed for their cognitive development and ability.

\section{Statistical analysis}

The primary endpoint will be analyzed using both the intention-to-treat population (children lost to follow-up or referred at hospital considered as failures) and the perprotocol population (including only children without protocol deviation). A third analysis will be conducted using the last value available (endpoint analysis). A chi-squared test will be used to compare the primary endpoint (recovery at 3 months) between the three groups.

To take into account the time to recovery, a survival analysis will be performed using a Cox model with adjustment for center and age. Comparisons will be also performed for the other anthropometric criteria (weight, height, MUAC, weight gain) as well as for a DMC II test using a mixed linear model for repeated measurements.

\section{Bioinformatic analysis}

For the stool samples, bioinformatics analysis will be conducted to identify the species present in each sample. As many species can exist in the same sample, samples will be clustered in "profiles" of composition using principal component analysis. In the first step, these profiles will be considered classes of a parameter called "microbiota." However, some specific species could impact the renutrition process more deeply. A second round of analysis will be conducted using the species themselves, taking into account the comparison of groups of children with rapid versus slow recovery. At the time of inclusion (day 0 ), analysis will focus on (1) comparison of microbiota between countries, (2) association of some socioeconomic parameters with some specific profile of microbiota (all countries together), and (3) differences in microbiota between children with or without malnutrition (for children aged over 18 months). During the time course of the renutrition process, comparison of microbiota will be done (1) between the arms of treatment, (2) between children with and without recovery, and (3) between children with slow and fast recovery.

\section{Discussion}

Child malnutrition is a major public health problem in intertropical zones, but most of the resources and studies focus on SAM due to its life-threatening impact. However, SAM develops most often with chronic malnutrition that can lead to moderate acute malnutrition during shortening of family resources or during child infections, before worsening into SAM. MAM thus has a heavy impact on national health structures, as the number of children involved is usually higher than that for SAM, and acting effectively on MAM could prevent having to treat more SAM. The delay in seeking treatment is also often long, causing the situation to worsen and complicating treatment. Compliance to treatment is also a challenge. Facing these problems, almost no change in the strategy of treatment has been validated for the last 30 years. Decreasing the time of treatment and improving the efficacy could be major achievements.

MAM occurrence is almost exclusively restricted to the first 24 months of life, closely relating to the time when foods complementary to breast milk are introduced. However, recent studies on gut physiology have drawn attention to the role of dis-equilibrated gut microbiota both in malnutrition and obesity. We decided to use two strategies 
(prebiotics and antibiotics) to modulate the microbiota while providing renutrition with flours.

A short-term effect of antibiotics on nutritional recovery rate was observed in children treated for severe malnutrition. The effect on MAM could be similar. On the other hand, prebiotics serve as substrates and induce proliferation of bifidobacteria and lactobacilli, changing the proportions of different groups of bacteria in the gut. Other strategies could be envisioned, such as the use of anti-oxidants, specific micronutrients, etc.

Overall, we currently have only a partial understanding of interactions between nutrients, gut microorganisms and the immune system. Thus, we have chosen a pragmatic approach for the MALINEA study with two strategies targeting the gut microbiota in a broad manner. They are safe and practical to use at the community level in LMICs. Considering the large number of children concerned, criteria such as low prices, ease of use, and potential availability of local production, are very important for the choice of a strategy.

This three-armed randomized intervention will be evaluated by effects both on the children's anthropometric parameters and on their microbiota, providing first insights into the underlying mechanisms linking MAM, nutritional recovery and microbiota composition. This study received approval from the National Ethic Committees of the four host countries as well as from the Internal Review Board of the Pasteur Institute in Paris.

\section{Trial status}

ClinicalTrials.gov, ID: NCT03474276 Last update on 28 May 2018.

\section{Additional file}

Additional file 1: Standard Protocol Items: Recommendations for Interventional Trials (SPIRIT) 2013 Checklist: recommended items to address in a clinical trial protocol and related documents*. (DOC $122 \mathrm{~kb}$ )

\section{Abbreviations \\ ACF: Action Contre la Faim; CAR: Central African Republic; CM: Chronic malnutrition; CRENAM: Centre de RENutrion re-Adaptation des Malnutris; DMC II: Developmental Milestones Checklist II; FOS: Fructo-oligosaccharides; GAM: Global acute malnutrition; GOS: Galacto-oligosaccharides; MALINEA: Malnutrition et Infection de l'Enfance en Afrique; MAM: Moderate acute malnutrition; MUAC: Mid-upper-arm circumference; NGO: Nongovernmental organization; OTU: Operational Taxonomic Unit; PEC-MAM: Prise en Charge de la MAM; Q-PCR: Quantitative polymerase chain reaction; SAM: Severe acute malnutrition; SD: Standard deviation; WHZ: Weight-for-height Z-score}

\section{Acknowledgements}

The authors thank all the local staff involved in the registration of the children, the medical staff of the Health Ministry and the colleagues of the four French Embassies supporting the project. This is a collaborative project named MALINEA for "MAInutrition et INfection de I'ENfance en Afrique".

\section{Funding}

The MALINEA project is funded by a grant from the French Foreign Office (MEAE 27 rue de la Convention 75732 Paris Cedex 15) through a Fond de Solidarité Prioritaire (FSP) n² 2101375618 (3 November 2014) and a grant from the Action against Hunger international foundation.

\section{Availability of data and materials}

Data sharing is not applicable to this article, as no datasets were generated or analyzed at this stage of the current study. The datasets generated and/or analyzed during the trial will not be publicly available due to confidentiality but will be available from the corresponding author on reasonable request.

\section{Authors' contributions}

MV, BGH, PA, and CVP wrote the protocol. LT prepared the databases. AM, $\mathrm{RR}$, and $\mathrm{HM}$ gave details on local epidemiology and organized the project in details on the field; $A B, M A$, and $R J$ gave expert advice on the choice of intervention. RJ coordinated the whole MALINEA project. All authors read and approved the final manuscript.

\section{Ethics approval and consent to participate}

This study was conducted according to the protocol and ethical principles with their origins in the Declaration of Helsinki. The research protocol was approved by (1) the FDA-approved IRB (Institutional Review Board) and the CoRC (Clinical Research Committee) of Institut Pasteur, (2) the National Ethics Committee of the four countries, and (3) the CCTIRS (Comité Consultatif sur le Traitement de l'Information en matière de Recherche dans le domaine de la santé) and the CNIL (Commission Nationale de I'Information et des Libertés) in France. Written informed consent will be obtained from all children's parents or legal guardians for both MAM and well-nourished children. The project will provide treatment and laboratory testing free of charge. An international insurance contract is already granted to cover all specific risk of the trial.

\section{Consent for publication}

Not applicable.

\section{Competing interests}

The authors declare that they have no competing interests. The funders had no role in the design of the protocol.

\section{Publisher's Note}

Springer Nature remains neutral with regard to jurisdictional claims in published maps and institutional affiliations.

\section{Author details}

'Unité d'Epidémiologie des Maladies Infectieuses, Institut Pasteur Dakar, Dakar, Senegal. ²Unité des Epidémies et des Maladies Emergentes, Institut Pasteur, 25 Rue du Dr. Roux, 75015 Paris, France. ${ }^{3}$ Unité d'Epidémiologie Institut Pasteur de Bangui, Bangui, Central African Republic. ${ }^{4}$ Unité d'Epidémiologie, Institut Pasteur de Madagascar, BP1274, 101 Antananarivo, Madagascar. ${ }^{5}$ Unité d'Epidémiologie CERMES, Niamey „, Niger. ${ }^{6}$ Department of Nutrition, Exercise and Sports, Faculty of Science, University of Copenhagen, Rolighedsvej 30, DK-1958 Frederiksberg, Denmark. ${ }^{7}$ Tampere Centre for Child Health Research, University of Tampere, Lääkärinkatu 1, 33014 Tampere, Finland. ${ }^{8}$ Centre de recherche Transactionnel, Institut Pasteur, 28 Rue du Dr. Roux, 75015 Paris, France. ${ }^{9}$ Action Contre la Faim, 14/16 Boulevard Douaumont - CS 80060, PARIS CEDEX 17, 75854 Paris, France. ${ }^{10}$ Department of Parasites and Vector Insects, Institut Pasteur, 28 Rue du Dr. Roux, 75015 Paris, France.

Received: 20 April 2018 Accepted: 29 October 2018

Published online: 04 December 2018

\section{References}

1. Anuradha R, Munisankar S, Bhootra Y, Kumar NP, Dolla C, Kumaran P, Babu $\mathrm{S}$. Coexistent malnutrition is associated with perturbations in systemic and antigen-specific cytokine responses in latent tuberculosis infection. Clin Vaccine Immunol. 2016;23:339-45. https://doi.org/10.1128/CVI.00009-16.

2. Crane RJ, Jones KDJ, Berkley JA. Environmental enteric dysfunction an overview. CMAM FORUM Technical Brief. 2014.

3. Gaayeb L, Pinçon C, Cames C, Sarr JB, Seck M, Schacht AM, Remoué F, Hermann E, Riveau G. Immune response to Bordetella pertussis is associated 
with season and undernutrition in Senegalese children. Vaccine. 2014;32: 3431-7. https://doi.org/10.1016/j.vaccine.2014.03.086.

4. Anonymous. Enquête nationale sur le suivi des indicateurs des objectifs du Millénaire pour le développement durable 2012-2013. Madagascar: INSTAT; 2014.

5. Briend A, Prinzo ZW. Dietary management of moderate malnutrition: time for a change. Food Nutr Bull. 2009;30:5265-6.

6. Lazzerini M, Rubert L, Pani P. Specially formulated foods for treating children with moderate acute malnutrition in low- and middle-income countries. Cochrane Database Syst Rev. 2013;6:CD009584. https://doi.org/10.1002/ 14651858.CD009584.pub2.

7. Lenters LM, Wazny K, Webb P, Ahmed T, Bhutta ZA. Treatment of severe and moderate acute malnutrition in low- and middle-income settings: a systematic review, meta-analysis and Delphi process. BMC Public Health. 2013;13:S23. https://doi.org/10.1186/1471-2458-13-S3-S23.

8. Navarro-colorado C, Mason F, Shoham J. Network paper measuring the effectiveness of supplementary feeding programmes in emergencies. Humanit Pract Netw. 2008;44.

9. WHO. World Health Statistics. Geneva; 2017. http://www.who.int/newsroom/fact-sheets/detail/diarrhoeal-disease. Accessed Nov 2018.

10. UNICEF Data March 2018. https://data.unicef.org/wp-content/uploads/2018/ 02/CoD_Diarrhoea_Feb-2018_WHO_MCEE_234.xIsx. Accessed Nov 2018.

11. Hao CT, de Sessions $P$, Jie $S$, Pham Thanh $P$, Thompson CN, Nguyen Ngoc Minh C, Wenhan Chu C, Tran TA, Thomson NR, Thwaites GE, Rabaa MA, Hibberd M, Baker S. Assessing gut microbiota perturbations during the early phase of infectious diarrhea in Vietnamese children. Gut Microbes. 2017. https://doi.org/10.1080/19490976.2017.1361093.

12. Prendergast AJ, Kelly P. Interactions between intestinal pathogens, enteropathy and malnutrition in developing countries. Curr Opin Infect Dis. 2016;29:229-36.

13. Stiemsma LT, Michels KB. The role of the microbiome in the developmental origins of health and disease. Pediatrics. 2018;141:e20172437.

14. Laursen MF, Bahl MI, Michaelsen KF, Licht TR. First foods and gut microbes. Front Microbiol. 2017:8:356. https://doi.org/10.3389/fmicb.2017.00356.

15. De Filippo C, Cavalieri D, Di Paola M, Ramazzotti M, Poullet JB, Massart S. Impact of diet in shaping gut microbiota revealed by a comparative study in children from Europe and rural Africa. PNAS. 2010;107:14691-6.

16. Grześkowiak Ł, Collado MC, Mangani C, Maleta K, Laitinen K, Ashorn P. Distinct gut microbiota in Southeastern African and Northern European infants. J Pediatr Gastroenterol Nutr. 2012;54:812-6. https://doi.org/10.1097/ MPG.0b013e318249039c.

17. Yatsunenko T, Rey FE, Manary MJ, Trehan I, Dominguez-Bello MG, Contreras $M$, et al. Human gut microbiome viewed across age and geography. Nature. 2012;486:222-7. https://doi.org/10.1038/nature11053.

18. Ghosh TS, Gupta SS, Bhattacharya T, Yadav D, Barik A, Chowdhury A, et al. Gut microbiomes of Indian children of varying nutritional status. PLoS One. 2014:9:e95547.

19. Kane AV, Dinh DM, Ward HD. Childhood malnutrition and the intestinal microbiome. Pediatr Res. 2015;77:256-62.

20. Million M, Tidjani Alou M, Khelaifia S, Bachar D, Lagier JC, Dione N, et al. Increased gut redox and depletion of anaerobic and methanogenic prokaryotes in severe acute malnutrition. Sci Rep. 2016;6:26051. https://doi. org/10.1038/srep26051.

21. Monira S, Nakamura S, Gotoh K, Izutsu K, Watanabe H, Alam NH, et al. Gut microbiota of healthy and malnourished children in Bangladesh. Front Microbiol. 2011;2:228. https://doi.org/10.3389/fmicb.2011.00228.

22. Smith MI, Yatsunenko T, Manary MJ, Trehan I, Mkakosya R, Cheng J, et al. Gut microbiomes of Malawian twin pairs discordant for kwashiorkor. Science. 2013;339:548-54. https://doi.org/10.1126/science.1229000.

23. Subramanian S, Huq S, Yatsunenko T, Haque R, Mahfuz M, Alam M, et al. Persistent gut microbiota immaturity in malnourished Bangladeshi children. Nature. 2014;510:417-21. https://doi.org/10.1038/nature13421.

24. Velly H, Britton RA, Preidis GA. Mechanisms of cross-talk between the diet, the intestinal microbiome, and the undernourished host. Gut Microbes. 2017;8:98-112. https://doi.org/10.1080/19490976.2016.1267888.

25. Jain N, Walker WA. Diet and host-microbial crosstalk in postnatal intestinal immune homeostasis. Nat Rev Gastroenterol Hepatol. 2015;12:14-25.

26. Silva MJB, Carneiro MBH, dos Anjos Pultz B, Pereira Silva D, Lopes MEM, dos Santos LM. The multifaceted role of commensal microbiota in homeostasis and gastrointestinal diseases. J Immunol Res. 2015;2015:321241. https://doi. org/10.1155/2015/321241.

27. Britton RA, Young VB. Role of the intestinal microbiota in resistance to colonization by Clostridium difficile. Gastroenterology. 2014;146:1547-53.
28. Stecher $\mathrm{B}$. The roles of inflammation, nutrient availability and the commensal microbiota in enteric pathogen infection. Microbiol Spectr. 2015;3(3). https://doi.org/10.1128/microbiolspec.MBP-0008-2014.

29. Kostic AD, Xavier RJ, Gevers D. The microbiome in inflammatory bowel disease: current status and the future ahead. Gastroenterology. 2014;146: 1489-99.

30. Manichanh C, Borruel N, Casellas F, Guarner F. The gut microbiota in IBD. Nat Rev Gastroenterol Hepatol. 2012;9:599-608.

31. Marasco G, Di Biase AR, Schiumerini R, Eusebi LH, lughetti $L$, Ravaioli $F$, et al. Gut microbiota and celiac disease. Dig Dis Sci. 2016. https://doi.org/10.1007/ s10620-015-4020-2.

32. Bohm M, Siwiec RM, Wo JM. Diagnosis and management of small intestinal bacterial overgrowth. Nutr Clin Pract. 2013;28:289-99.

33. Hughes PA, Zola H, Penttila IA, Blackshaw LA, Andrews JM, Krumbiegel D. Immune activation in irritable bowel syndrome: can neuroimmune interactions explain symptoms? Am J Gastroenterol. 2013;108:1066-74.

34. Di Mauro A, Neu J, Riezzo G, Raimondi F, Martinelli D, Francavilla R, Indrio F. Gastrointestinal function development and microbiota. Ital J Pediatr. 2013;24:15.

35. Atarashi K, Tanoue T, Oshima K, Suda W, Nagano Y, Nishikawa H, Fukuda S, Saito T, Narushima S, Hase K, Kim S, Fritz JV, Wilmes P, Ueha S, Matsushima K, Ohno H, Olle B, Sakaguchi S, Taniguchi T, Morita H, Hattori M, Honda K. Treg induction by a rationally selected mixture of Clostridia strains from the human microbiota. Nature. 2013;500:232-6.

36. Schwabe RF, Jobin C. The microbiome and cancer. Nat Rev Cancer. 2013;13: 800-12.

37. Stringer AM, Al-Dasooqi N, Bowen JM, Tan TH, Radzuan M, Logan RM, Mayo B, Keefe DM, Gibson RJ. Biomarkers of chemotherapy-induced diarrhoea: a clinical study of intestinal microbiome alterations, inflammation and circulating matrix metalloproteinases. Support Care Cancer. 2013;21:1843-52.

38. Zhao L. The gut microbiota and obesity: from correlation to causality. Nat Rev Microbiol. 2013;11:639-47.

39. Khan MT, Nieuwdorp M, Bäckhed F. Microbial modulation of insulin sensitivity. Cell Metab. 2014;20:753-60.

40. Dinh DM, Ramadass B, Kattula D, Sarkar R, Braunstein P, Tai A, et al. Longitudinal analysis of the intestinal microbiota in persistently stunted young children in South India. PLoS One. 2016;11:e0155405. https://doi.org/ 10.1371/journal.pone.0155405.

41. Bartelt LA, Bolick DT, Mayneris-Perxachs J, Kolling GL, Medlock GL, Zaenker El, et al. Cross-modulation of pathogen-specific pathways enhances malnutrition during enteric co-infection with Giardia lamblia and enteroaggregative Escherichia coli. PLoS Pathog. 2017;13:e1006471. https:// doi.org/10.1371/journal.ppat.1006471.

42. Moloney RD, Desbonnet L, Clarke G, Dinan TG, Cryan JF. The microbiome: stress, health and disease. Mamm Genome. 2014;25(1-2):49-74. https://doi. org/10.1007/s00335-013-9488-5.

43. Lyte M. Microbial endocrinology in the microbiome-gut-brain axis: how bacterial production and utilization of neurochemicals influence behavior. PLoS Pathog. 2013;9:11.

44. Qureshi IA, Mehler MF. Towards a "systems"-level understanding of the nervous system and its disorders. Trends Neurosci. 2013;36:674-84.

45. Collins SM, Kassam Z, Bercik P. The adoptive transfer of behavioral phenotype via the intestinal microbiota: experimental evidence and clinical implications. Curr Opin Microbiol. 2013;16:240-5.

46. Hornig M. The role of microbes and autoimmunity in the pathogenesis of neuropsychiatric illness. Curr Opin Rheumatol. 2013;25:488-795.

47. Christie CD, Heikens GT, McFarlane DE. Nosocomial and community-acquired infections in malnourished children. J Trop Med Hyg. 1988;91:173-80.

48. Macdougall LG. The effect of aureomycin in undernourished African children. J Trop Pediatr. 1957;3:74-81.

49. Trehan I, Shulman RJ, Ou CN, Maleta K, Manary MJ. A randomized, doubleblind, placebo-controlled trial of rifaximin, a nonabsorbable antibiotic, in the treatment of tropical enteropathy. Am J Gastroenterol. 2009;104:2326-33.

50. Trehan I, Goldbach HS, LaGrone LN, Meuli GJ, Wang RJ, Maleta KM, Manary MJ. Antibiotics as part of the management of severe acute malnutrition. $N$ Engl J Med. 2013;368:425-35.

51. Isanaka S, Langendorf C, Berthé F, Gnegne S, Li N, Ousmane N, Harouna S, Hassane H, Schaefer M, Adehossi E, Grais RF. Routine amoxicillin for uncomplicated severe acute malnutrition in children. N Engl J Med. 2016; 374:444-53 
52. Berkley JA, Ngari M, Thitiri J, Mwalekwa L, Timbwa M, Hamid F, Ali R, Shangala J, Mturi N, Jones KDJ, Alphan H, Mutai B, Bandika V, Hemed T, Awuondo K, Morpeth S, Kariuki S, Fegan G. Daily co-trimoxazole prophylaxis to prevent mortality in children with complicated severe acute malnutrition: a multicentre, double-blind, randomised placebo-controlled trial. Lancet Glob Health. 2016;4:e464-73. https://doi.org/10.1016/S2214-109X(16)30096-1.

53. Lazzerini M, Tickell D. Antibiotics in severely malnourished children: systematic review of efficacy, safety and pharmacokinetics. Bull World Health Organ. 2011;89(8):594-607. https://doi.org/10.2471/BLT.10.084715.

54. Shirajum M, Shota N, Kazuyoshi G, Kaori I, Watanabe H, Alam NH, Nakaya T, Horii T, Ali SI, lida T, Alam M. Metagenomic profile of gut microbiota in children during cholera and recovery. Gut Pathogens. 2013;5:1.

55. Isanaka S, Adehoss E, Grais RF. Amoxicillin for severe acute malnutrition in children. N Engl J Med. 2016;375:191-2. https://doi.org/10.1056/ NEJMC1605388.

56. Million M, Lagier JC, Raoult D. Meta-analysis on efficacy of amoxicillin in uncomplicated severe acute malnutrition. Microb Pathog. 2017;106:76-77. https://doi.org/10.1016/j.micpath.2016.06.025.

57. Okeke IN, Cruz JR, Keusch GT, and Alliance for the Prudent Use of Antibiotics-Nutrition Group. Antibiotics for uncomplicated severe malnutrition. N Engl J Med. 2013;368:2435-6. https://doi.org/10.1056/ NEJMc1304407\#SA2.

58. Rawson TM, Moore LS, Holmes AH. Amoxicillin for severe acute malnutrition in children. N Engl J Med. 2016;375:190-1. https://doi.org/10.1056/ NEJMC1605388\#SA1.

59. Trehan I, Schechtman KB, Manary MJ. Amoxicillin for severe acute malnutrition in children. N Engl J Med. 2016;375:191. https://doi.org/10. 1056/NEJMc1605388\#SA2.

60. Williams PC, Berkley JA. Severe acute malnutrition update: current WHO guidelines and WHO essential medicine list for children. 2016. http://www. who.int/selection_medicines/committees/expert/21/applications/s6_paed_ antibiotics_appendix7_sam.pdf. Accessed 1 June 2017.

61. Drissi F, Buffet $S$, Raoult D, Merhej V. Common occurrence of antibacterial agents in human intestinal microbiota. Front Microbiol. 2015;6:441. https:// doi.org/10.3389/fmicb.2015.00441.

62. Langdon A, Crook N, Dantas G. The effects of antibiotics on the microbiome throughout development and alternative approaches for therapeutic modulation. Genome Med. 2016;8:39.

63. Luntamo M, Kulmala T, Cheung YB, Maleta K, Ashorn P. The effect of antenatal monthly sulphadoxine-pyrimethamine, alone or with azithromycin, on foetal and neonatal growth faltering in Malawi: a randomised controlled trial. Trop Med Int Health. 2013;18:386-97.

64. Keenan JD, Bailey RL, West SK, Arzika AM, Hart J, Weaver J, Kalua K, Mrango Z, Ray KJ, Cook C, Lebas E, O'Brien KS, Emerson PM, Porco NZ, and Lietman TM for the MORDOR Study Group. Azithromycin to reduce childhood mortality in Sub-Saharan Africa. N Engl J Med. 2018;378:1583-92. https://doi. org/10.1056/NEJMoa1715474

65. Bisanz JE, Enos MK, PrayGod G. Microbiota at multiple body sites during pregnancy in a rural Tanzanian population and effects of moringasupplemented probiotic yogurt. Appl Environ Microbiol. 2015;81:4965-75.

66. Charbonneau MR, O'Donnell D, Blanton LV. Sialylated milk oligosaccharides promote microbiota-dependent growth in models of infant undernutrition. Cell. 2016;164:859-71.

67. Blanton LV, Barratt MJ, Charbonneau MR, Ahmed T, Gordon Jl. Childhood undernutrition, the gut microbiota, and microbiota-directed therapeutics. Science. 2016;352:1533.

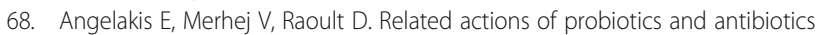
on gut microbiota and weight modification. Lancet Inf Dis. 2013;13:889-99.

69. Kerac M, Bunn J, Seal A, Thindwa M, Tomkins A, Sadler K, Bahwere P, Collins S. Probiotics and prebiotics for severe acute malnutrition (PRONUT study): a doubleblind efficacy randomised controlled trial in Malawi. Lancet. 2009;374:136-44.

70. Slattery DF, MacFabe F, Frye RE. The Significance of the enteric microbiome on the development of childhood disease: a review of prebiotic and probiotic therapies in disorders of childhood. Clin Med Ins Ped. 2016;10:91-107

71. Firmansyah A, Chongviriyaphan N, Dillon DHS, Khan NC, Morita T, Tontisirin K, Tuyen L, Wang W, Bindels J, Deurenberg P, Ong S, Hautvast J, Meyer D, Vaughan EE. Fructans in the first 1000 days of life and beyond, and for pregnancy. Asia Pac J Clin Nutr. 2016;25:652-75.

72. Franco-Robles E, López MG. Implication of fructans in health: immunomodulatory and antioxidant mechanisms. Sci World J. 2015:289267.
73. Kolida S, Tuohy K, Gibson GR. Prebiotic effects of inulin and oligofructose. $\mathrm{Br}$ J Nutr. 2002;87(Suppl 2):S193-7. https://doi.org/10.1079/BJNBJN/2002537.

74. Roberfroid M, Gibson GR, Hoyles L, McCartney AL, Rastall R, Rowland I, et al. Prebiotic effects : metabolic and health benefits. CentAUR. 2010;104:S1-63. https://doi.org/10.1017/S0007114510003363.

75. Dewulf EM, Cani PD, Claus SP, Fuentes S, Puylaert PGB, Neyrinck AM, et al. Insight into the prebiotic concept: lessons from an exploratory, double blind intervention study with inulin-type fructans in obese women. Gut. 2013:62:1112-21.

76. Piemontese P, Giannı ML, Braegger CP, Chirico G, Gruber C. Tolerance and safety evaluation in a large cohort of healthy infants fed an innovative prebiotic formula: a randomized controlled trial. PLoS ONE. 2011;6:e28010. https://doi.org/10.1371/journal.pone.0028010.

77. Gibson GR, Beatty ER, Wang X, Cummings $\mathrm{JH}$. Selective stimulation of bifidobacteria in the human colon by oligofructose and inulin. Gastroenterology. 1995;108:975-82.

78. Meyer D, Stasse-Wolthuis M. The bifidogenic effect of inulin and oligofructose and its consequences for gut health. Eur J Clin Nutr. 2009;63:1277-89.

79. Ramirez-Farias C, Slezak K, Fuller Z, Duncan A, Holtrop G, Louis P. Effect of inulin on the human gut microbiota: stimulation of Bifidobacterium adolescentis and Faecalibacterium prausnitzii. Br J Nutr. 2009;101:541-50.

80. Chung WSF, Walker AW, Louis P, Parkhil J, Vermeiren J, Bosscher D, et al. Modulation of the human gut microbiota by dietary fibres occurs at the species level. BMC Biol. 2016;14:3.

81. Jung $\mathrm{TH}$, Jeon WM, Han KS. In vitro effects of dietary inulin on human fecal microbiota and butyrate production. J Microbiol Biotechnol. 2015;25:1555-8.

82. Orel R, Kamhi Trop T. Intestinal microbiota, probiotics and prebiotics in inflammatory bowel disease. World J Gastroenterol. 2014;20:11505-24.

83. Steed H, Macfarlane GT, Blackett KL, Bahrami B, Reynolds N, Walsh SV, Cummings $\mathrm{JH}$, Macfarlane S. Clinical trial: the microbiological and immunological effects of symbiotic consumption - a randomized doubleblind placebo-controlled study in active Crohn's disease. Aliment Pharmacol Ther. 2010;32:872-83. https://doi.org/10.1111/j.1365-2036.2010.04417.x.

84. Anonymous. Key outcomes of the Technical Meeting on Environmental Enteric Dysfunction, the Microbiome Undernutrition. Vienna: IAEA; 2015.

85. Anonymous. World Gastroenterology Organisation. Practical recommandations: Probiotiques et Prébiotiques. Mai 2008

86. Rivera-Huerta M, Lizárraga-Grimes VL, Castro-Torres IG, Tinoco-Méndez M, Macías-Rosales L, Sánchez-Bartéz F, Tapia-Pérez GG, Romero-Romero L, Gracia-Mora Ml. Functional effects of prebiotic fructans in colon cancer and calcium metabolism in animal models. Biomed Res Int. 2017;2017:975-82. https://doi.org/10.1155/2017/9758982.

87. Roberfroid MB. Inulin-type fructans: functional food ingredients. J Nutr. 2007;137:2493S-502S.

88. Dehghan P, Farhangi MA, Tavakoli F, Aliasgarzadeh A, Akbari AM. Impact of prebiotic supplementation on T-cell subsets and their related cytokines, anthropometric features and blood pressure in patients with type 2 diabetes mellitus: a randomized placebo-controlled Trial. Complement Ther Med. 2016;24:96-102. https://doi.org/10.1016/j.ctim.2015.12.010.

89. Liu J, Hanlon A, Ma C, Zhao SR, Cao S, Compher C. Low blood zinc, iron, and other sociodemographic factors associated with behavior problems in preschoolers. Nutrients. 2014;6:530-45. https://doi.org/10.3390/nu6020530.

90. Sandjaja, Poh BK, Rojroonwasinkul N, Le Nyugen BK, Budiman B, Ng LO, Soonthorndhada K, Xuyen HT, Deurenberg P, Parikh P, SEANUTS Study Group. Relationship between anthropometric indicators and cognitive performance in Southeast Asian school-aged children. Br J Nutr. 2013;110: S57-64. https://doi.org/10.1017/S0007114513002079.

91. Goyala MS, Venkateshb S, Milbrandt J, Gordon JI, Raichl ME. Feeding the brain and nurturing the mind: linking nutrition and the gut microbiota to brain development. PNAS. 2015;112:14105-12.

92. Madore C, Leyrolle Q, Lacabanne C, Benmamar-Badel A, Joffre C, Nadjar A Layé S. Neuroinflammation in autism: plausible role of maternal inflammation, dietary omega 3, and microbiota. Neural Plasticity. 2016; 3597209:15.

93. Bhoite RM, lyer UM. Effect of deworming vs Iron-Folic acid supplementation plus deworming on growth, hemoglobin level, and physical work capacity of schoolchildren. Indian Pediatr. 2012;49:659-61.

94. Marchand V. Using probiotics in the paediatric population. Paediatr Child Health. 2012;17:575-6.

95. Versalovic J. The human microbiome and probiotics: implications for pediatrics. Ann Nutr Metab. 2013;63(Suppl 2):42-52. 
96. Bested AC, Logan AC, Selhub EM. Intestinal microbiota, probiotics and mental health: from Metchnikoff to modern advances: part III-convergence toward clinical trials. Gut Pathog. 2013;16:4.

97. Davari S, Talaei SA, Alaei H, Salami M. Probiotics treatment improves diabetes-induced impairment of synaptic activity and cognitive function: behavioral and electrophysiological proofs for microbiome-gut-brain axis. Neuroscience. 2013;14:287-96.

98. Akombi BJ, Agho KE, Merom D, Renzaho AM, Hall JJ. Child malnutrition in sub-Saharan Africa: a meta-analysis of demographic and health surveys (2006-2016). PLoS One. 2017;12:e0177338. https://doi.org/10.1371/journal. pone. 0177338 .

99. Wuehler SE, Biga Hassoumi A. Situational analysis of infant and young child nutrition policies and programmatic activities in Niger. Matern Child Nutr. 2011;7:133-56. https://doi.org/10.1111/j.1740-8709.2010.00307.x.

100. Kouassi F. Study on the underlying causes for under-nutrition, Department of Mayahi, Region of Maradi, November 2016 to March 2017. Link Unit NCA, Action Against Hunger, May 2017. http://inknca.org/Communaute.htm?lng=en.

101. Anonymous. Evaluation de la situation nutritionnelle par la méthodologie SMART au Niger. Institut National de la Statistique. Rapport final, novembre 2016.

102. Anonymous. Enquête Démographique et de Santé à Indicateurs Multiples 2010-2011. Agence Nationale de la Statistique et de la Démographie du Sénégal. Ministère de la Santé Publique, Dakar 2012.

103. Caleo GM, Sy AP, Balandine S, Polonsky J, Palma PP, Grais RF, Checchi F. Sentinel site community surveillance of mortality and nutritional status in southwestern Central African Republic, 2010. Popul Health Metr. 2012;10:18.

104. Breurec S, Vanel N, Bata P, Chartier L, Farra A, Favennec L, Vray M. Etiology and epidemiology of diarrhea in hospitalized children from low income country: a matched case-control study in Central African Republic. PLoS Negl Trop Dis. 2016;10:e0004283. https://doi.org/10.1371/journal.pntd.0004283.

105. Enenkel M, See L, Karner M, Alvarez M, Rogenhofer E, Baraldes-Vallverdu C, Lanusse C, Salse N. Food security monitoring via mobile data collection and remote sensing: results from the Central African Republic. PLoS One. 2015; 10:e0142030.

106. Wakabi W. Health crisis worsens in Central African Republic. Lancet. 2006; 367:1969-70.

107. Golden M. Proposed recommended nutrient densities for moderately malnourished children. Food Nutr Bull. 2009:30:5267-342.

108. Wilson B, Whelan K. Prebiotic inulin-type fructans and galactooligosaccharides: definition, specificity, function, and application in gastrointestinal disorders. J Gastroenterol Hepatol. 2017;32:64-8. https://doi. org/10.1111/jgh.13700.

109. Healey G, Murphy R, Butts C, Brough L, Whelan K, Coad J. Habitual dietary fibre intake influences gut microbiota response to an inulin-type fructan prebiotic: a randomised, double-blind, placebo-controlled, cross-over, human intervention study. Br J Nutr. 2018;119:176-89. https://doi.org/10 1017/S0007114517003440 Epub 2018 Jan.

Ready to submit your research? Choose BMC and benefit from:

- fast, convenient online submission

- thorough peer review by experienced researchers in your field

- rapid publication on acceptance

- support for research data, including large and complex data types

- gold Open Access which fosters wider collaboration and increased citations

- maximum visibility for your research: over $100 \mathrm{M}$ website views per year

At BMC, research is always in progress.

Learn more biomedcentral.com/submissions 